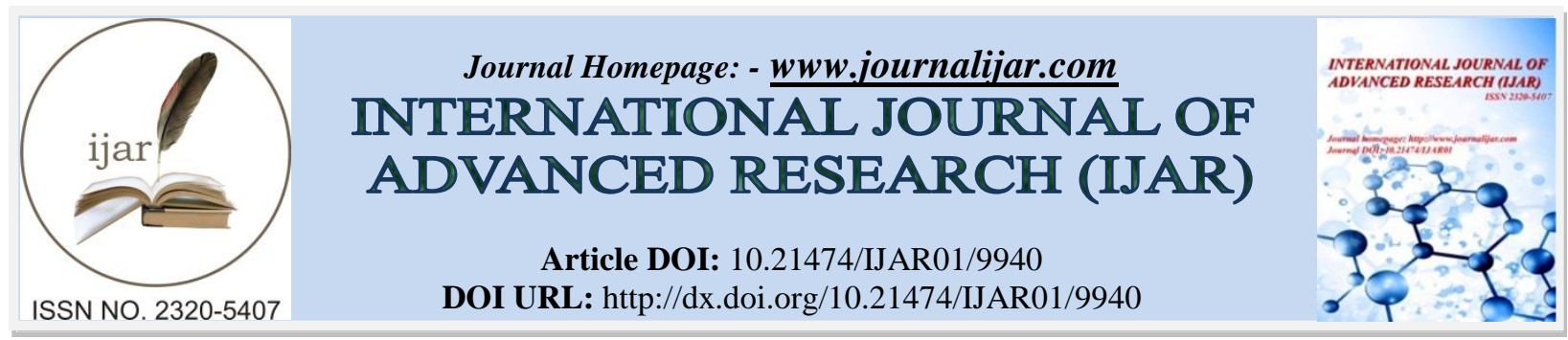

RESEARCH ARTICLE

\title{
GETTING THE RIGHT TO MAKE A NEW SHEPHERD TO USE THE OPPORTUNITIES OF THE MECHANISM OF MODERN CREATIVE TECHNOLOGIES.
}

\author{
Abdurahmanov O.Sh, Siddikov P.S and Yangiboyev R.M. \\ Termez branch of Tashkent State Technical University named after Islam Karimov.
}

\section{Manuscript Info}

\section{Manuscript History}

Received: 18 August 2019

Final Accepted: 20 September 2019

Published: October 2019

\section{Key words:-}

body twine, rope, weaving, texture, knitting, wrapping, satin knitting, satin weaving, standard, weaving loom, rapport, roll, coating, knitting pattern, coordinate axis, diagonal, glossy texture, foundation, method, candle, seamless machine.

\begin{abstract}
In the article we have developed a method for creating new patterns and designs of Sarja, Satin (Atlas) T-shirts based on existing theory of welding techniques with the use of modern computerized cordless weaving machines. The peculiarity of this method of obtaining a knitting pattern is that under a certain law, a knitting Sarja, a torn-type Sarja, is chosen as a base. It is possible to obtain a new rotation pattern by placing the base axis in the coordinate arrows and diagonal arrows that are in between them. When creating a new knitting pattern, the base is formed by shifting the direction of movement of the joints, body, rope coatings in the base braiding cells. The base rotation placed in the center of the coordinate axis cannot be changed. The base around the obtissa and the ordinate and the diagonal axes are altered according to a specific law, until the design of the pattern is well polished. The base at the center of the coordinate axis indicates that the base bracket is reinforced once for all axes around the axis.

In the second variant of the method, the rotation pattern is adjusted by rotating the rotation sliding or coating clockwise or to the right of the base around the center. It is shown that different patterns can be obtained using the methods mentioned above. There is also a formula for defining the pattern of body and weave braiding patterns in the formation of these joints.
\end{abstract}

Copy Right, IJAR, 2019,. All rights reserved.

\section{Introduction:-}

Rational use of dressing modes is important in enhancing consumer properties of new textured shirts and other fabrics. Tissue joints are divided into four types. These consist of fundamental clusters [1], [2], and the ability to form infinitely more complex braiding patterns depending on the type of tissue they produce. Nowadays, there is a small amount of joy in the work of shaping different weaving textures. Up to 28 horns can be incorporated in modern sewing machines [3]. Increasing the number of rhizomes in the production will increase the design and attractiveness of the fabric. The competitiveness of the textile appearance depends on the design of the knitting. Only one type of headgear, for example, the Sarja 1/4 weave, can be mixed with the stranded Sarge 4/1, or by using the number of shifts, it can be formed from the same number of strands of different shapes and colors in a different texture.

Corresponding Author:-Abdurahmanov O.Sh.

Address:-Termez branch of Tashkent State Technical University named after Islam Karimov. 
The possibilities of the knitting machines of the modern weaving machines are much greater, with the body twisting rate up to $R_{-} t=28$, with the wheel $R_{-}$(a) $=6400$. Increase of the $R$ and displacement $C$ of these folds has a positive effect on their appearance and hygiene.

The dependence of the slope $\mathrm{S}=1$ and rapport $\mathrm{R}$ on the theory of spin-folding is expressed as follows: $\mathrm{RT}=\mathrm{Ra}, \mathrm{S}= \pm 1$

The minimum build-up rate should be three or more times in the Sarja Rocks, $3 \leq \mathrm{RT}=\mathrm{Ra}$

In this case it is necessary to have $\mathrm{R} 3$ otherwise it will not be possible to arrange the sowing.

With the use of modern equipment, it is also possible to create new regularities of the Sargean winding.

Development of $R_{-}(t)>R_{-}$as type of weaving on the basis of changing the ratio of body and rope ropes in construction.

Making patterns based on the first coating roll across the Rapport. Arrange the axes in the direction of the axes passing through the selected center of formation to create an optimal pattern. Increase the body and rope rope rackage by more than 12 current rivets.

The combination of the above methods 3 and 4 is formed as follows. First of all, its pattern for the pattern of recreation is drawn (Figure $1 \mathrm{a}$ ) and b)). Figure 1. a)). Figure 1 a) Preparation of its pattern for the creation of a new pattern of rotation in the presence of nine bases of rotation and Fig. 1. b) Provides preparation of the pattern for the twenty-five basic rehearsals for the newly created method of knitting pattern.

Depending on the number of threads in the base weaving, the templates will continue to increase with respect to the first one. The number of cells in the first drawing is always nine. If the pattern is to be increased after drawing a pattern, that is, to obtain a larger pattern design than in the previous one, the number of base brackets in the nine cells is increased once. As a result, the number of cells is twenty-five. Thus, in this method, the pattern can be calculated by combining the base joints with unlimited reinforcement when necessary, and by combining the base rotation with the need for combing.

When preparing (drawing) a pattern of construction patterns, the number of knobs, multicolored tool, the basis of the knitting rack and the pattern pattern are taken into account. Selected baseline drawings are drawn (for example, Sarja 1/4, 4-wrap capsule in Figure 1) (Figure 2). Then coordinate systems are used. From the center of the coordinates, the coordinate axes are drawn and the diagonal lines passing through the center of the coordinate axes are drawn, ie the base of the coordinate system is laid (Fig. 3).

In this method, the pattern pattern is placed on each side of the coordinate and diagonal axes, as shown in Figure 1 a). On the basis of the sparse and elongated Sarja curves, the pattern is created on the basis of the joint arrows and diagonal arrows, mixed tweezers, tandoor, arched.

The pattern is generated as follows. First, the base is placed in the center of the axis of the axial coordinate. At the end of the base Sarja's 1/4 rotation rack, the Slave Sarge 4/1 bends are placed on either side of the obtissa axis. Arrange the Srja 4/1 curve to the right and left of the obtissa axis from the center of gravity chosen by the pattern pattern (Figure 4).

Then the two-axis $4 / 1$ torsion bends on both sides of the axis of the ordinate are arranged in such a way that the symmetry of the pattern is outlined. Place the Srja 4/1 bracket at the top and bottom of the ordinate at the center of the ordinate, selected from the center of rotation (Fig. 5). The pattern according to the pattern is shown in Fig. 6, where the obverse 4/1 twisting obverse and the axis of the ordinate are fully positioned on both sides. Figure 7 shows a pattern drawn on the diagonal axis passing the center of the coil $1 / 4$ of the base in accordance with the pattern pattern. 
Figure 8 shows a pattern drawn on the diagonal axis passing the center of the coil $1 / 4$ of the base in accordance with the pattern pattern. Figure 9 shows a pattern drawn by two diagonal arrows that pass through the center of the coordinate axes of the base Sarge 1/4.

This pattern will continue if there is a need to increase the size of the pattern. Using the regularity of this method, it is possible to obtain different patterns in the texture, making the texture attractive and attractive. Using the same method, we present the Satin (Atlas) 5/3 curves (Fig. 11) by rotating the center axis and rotating along the diagonal axes. Figure 12 shows a copy of the shirt embroidery Dorne weaved in modern reproduction by placing the base on the coordinate and diagonal arrows according to the pattern.

In this case, the first base line is drawn, and the second one is drawn from the end of the rebound. Then the counterclockwise axes are positioned along the arrows in the direction indicated by the $S_{-}$(alternating) shift sequence. The same method can be used in another way. In this case, the rotation axes are placed first on the diagonal arrows of the base and then on the coordinate axes in the alternating motion. At the same time, the general rate of rotation can be determined as follows.

\section{Example 1:}

Spinner $1 / 4$ rotation is selected. The shift is assumed to be a variable $S= \pm 1$. Baseline Cutting Rope Ras $=5$ The best weaving pattern on the body and the rope is defined as follows:

RT.H.= Ra.H. $=\sum_{\mathrm{R}_{\mathrm{ac}}=1}^{\mathrm{n}} \mathrm{R}_{\mathrm{ac}} /$ Rac. $-2=$

$(\operatorname{Rac}+2$ Rобц. ас +2Rорд.ac. +4 Rдиог.ac $) /(\operatorname{Rac}-2) .=(5+2 \cdot 5+2 \cdot 5+4 \cdot 5) /(5-2)=15$ ип.

See: Baseline Rapport, Rdiog.as. - Reversal of base joints found in diagonal arrows, Robts.as - Reversal rods located on obtsissa axis, Rord.as - rudder repositioning on axinatin axis.

\section{Example 2:}

Fix the base brackets twice. At the same time, the first amplification of the body and rope raises is $\mathrm{K}=1$ and the second increase is $\mathrm{K}=2$, and so on. will be examined separately.

1. Based on the fact that the first amplification is considered above, we determine the rapport.

RT.H. $=$ Ra.H. $=(K \cdot 2 \mathrm{Rac})+\operatorname{Rac}=(1 \cdot 5 \cdot 2+5)=15$ thread.

Where $\mathrm{K}=1$

\section{Define the second reinforcement}

RT.H. $=$ Ra.H. $=(K \cdot 2 \mathrm{Rac})+\mathrm{Rac}=(2 \cdot 2 \cdot 5+5)=25$ thread

Where $\mathrm{K}=2$. There is an opportunity to increase $\mathrm{K}$ by the number of threads on the reel. In our example, if we make a tertiary loop increase, then K: 3: the pattern reversal is Rt.n. = Ra.n. $=35$ threads. So the formula has proof.

Where: Number that indicates how many times it has been enhanced.

This method is simple and easy to use, without the need for a separate formula for each amplification of the more comfortable folding detection.

See: Baseline Rapport, Rdiogas. - Reversal of base joints found in diagonal arrows, Robts.as - Reversal rods located on obtsissa axis, Rord.as - rudder repositioning on axinatin axis.

As can be seen from the above formula, this method has the law of rotation. The number determined by the pattern reversal is equal to the number of body and weft threads in the joints in Figures 10 and 11. This method is useful for designing and retrieving the cutting pattern. 
Figure 1 a):- Prepare a model for the creation of a new pattern of spinning in the presence of a nine-base welding rack.

\begin{tabular}{|l|l|l|}
\hline & & \\
\hline & & \\
\hline & & \\
\hline & & \\
& & \\
\hline
\end{tabular}

Figure 1b):-Prepare the model for the twenty-five baseline rip-offs to create a rotation pattern in the newly created method.

\begin{tabular}{|l|l|l|}
\hline & & \\
\hline & & \\
\hline & & \\
\hline & & \\
& & \\
& & \\
\hline
\end{tabular}

Figure 2:-The basis for the method being created is choosing the backend.

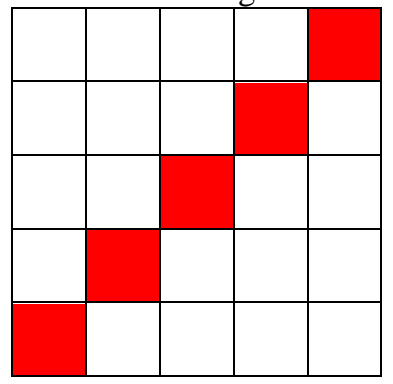


Figure 3:-Plant coordinate arrows and diagonal arrows from the selected center of gravity.
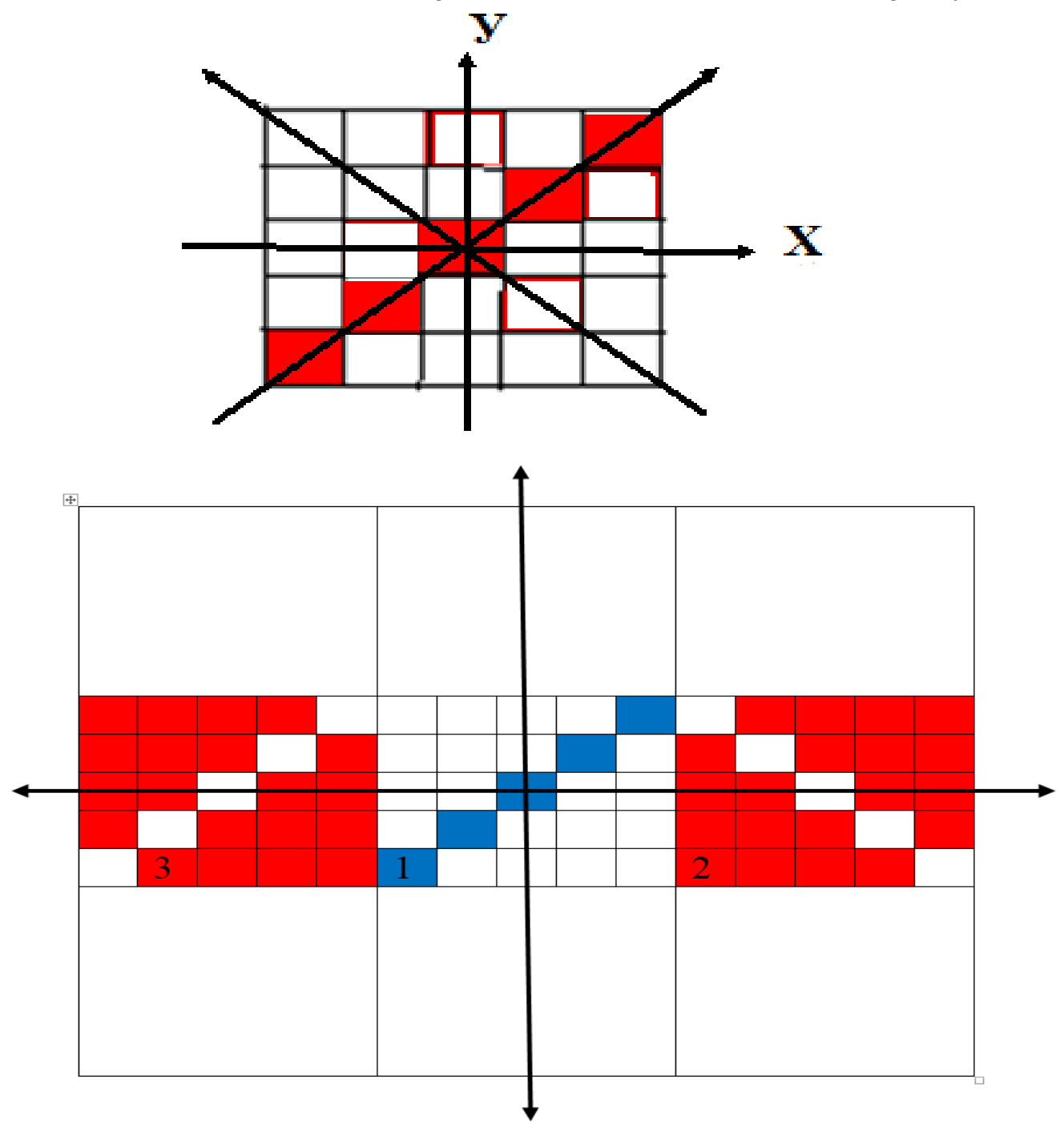

Figure 4:-Place Srja 4/1 brackets on the right and left of the obtissa axis from the center of gravity chosen by the pattern.

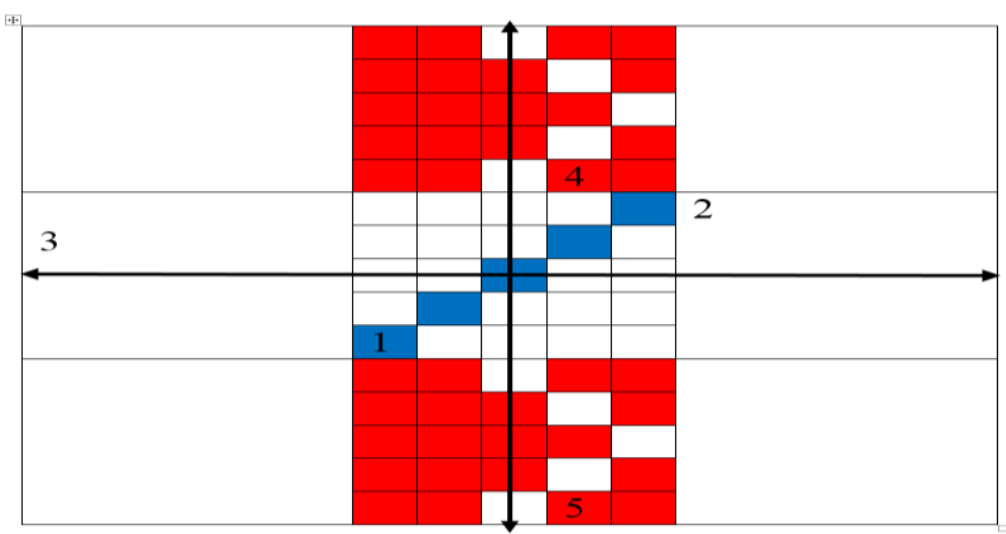

Figure 5:-Place the Srja 4/1 bracket on the top and bottom of the ordinate, from the center of gravity chosen by the pattern. 


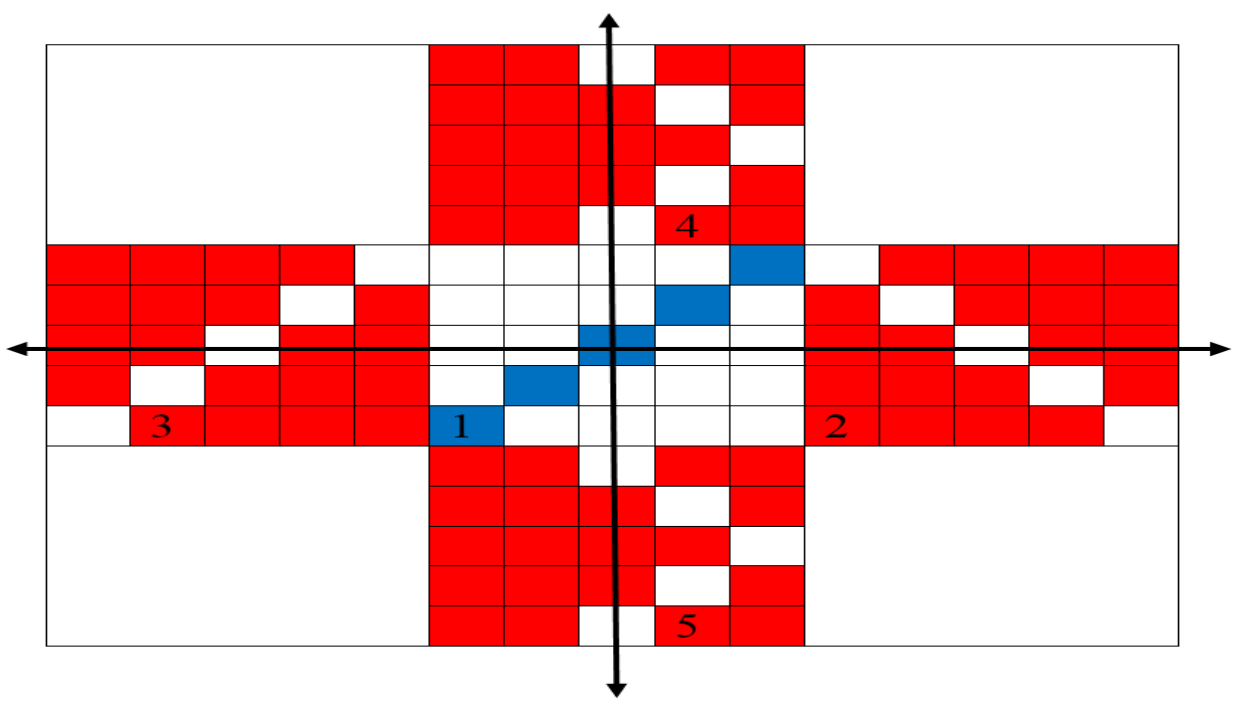

Figure 6:-The base according to the pattern is a rawing of the $4 / 1$ twisting obstruction and fully embedded on both sides of the axis.

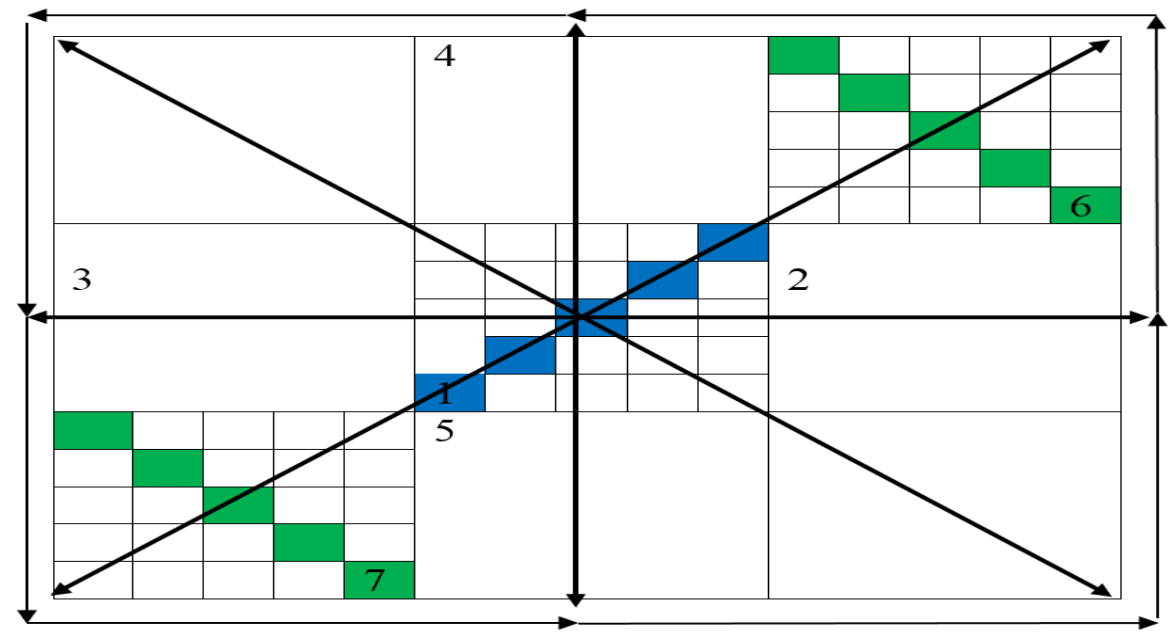

Figure 7:-The base according to the pattern is a pattern drawn on the diagonal axis passing the center of the coil axis of $1 / 4$ wrap.

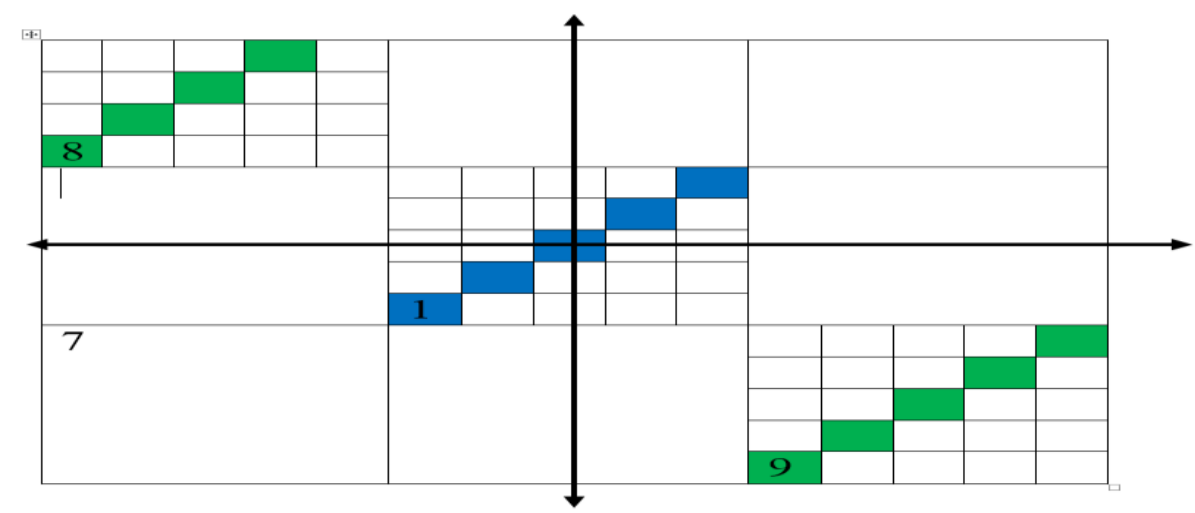

Figure 8:-The base according to the pattern is the pattern of the wrapping of 1/4 wrap fully placed on two diagonal arrows that pass through the center of the coordinate axes. 


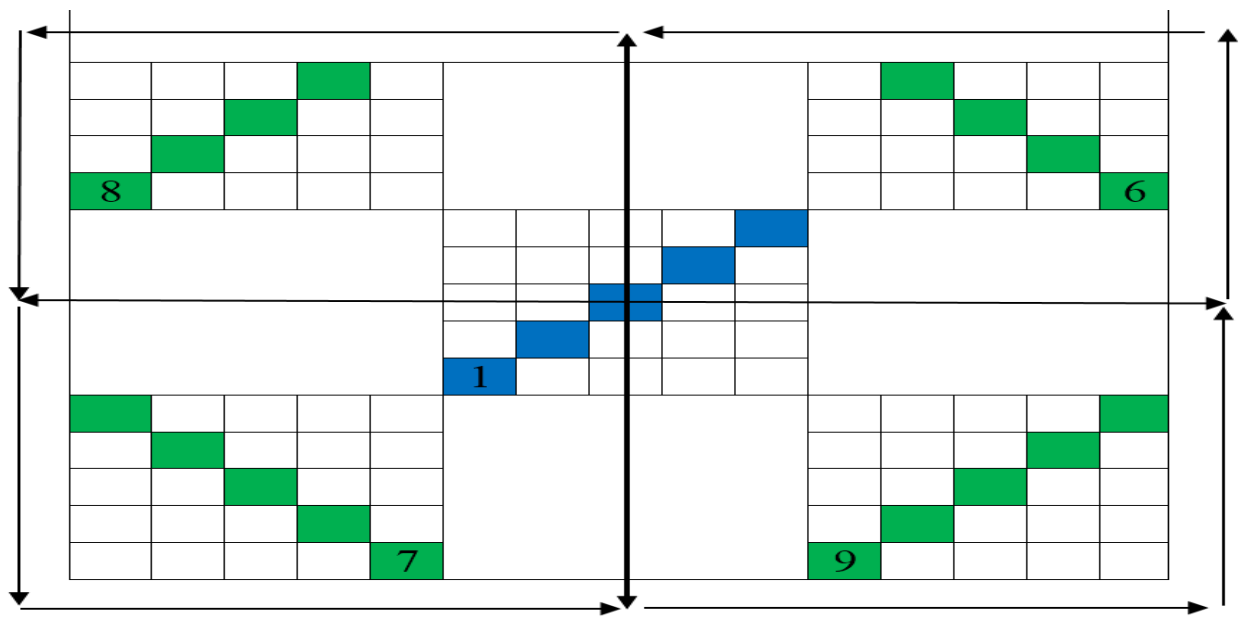

Figure 9:-The base according to the pattern passes through the center of the coordinate axes

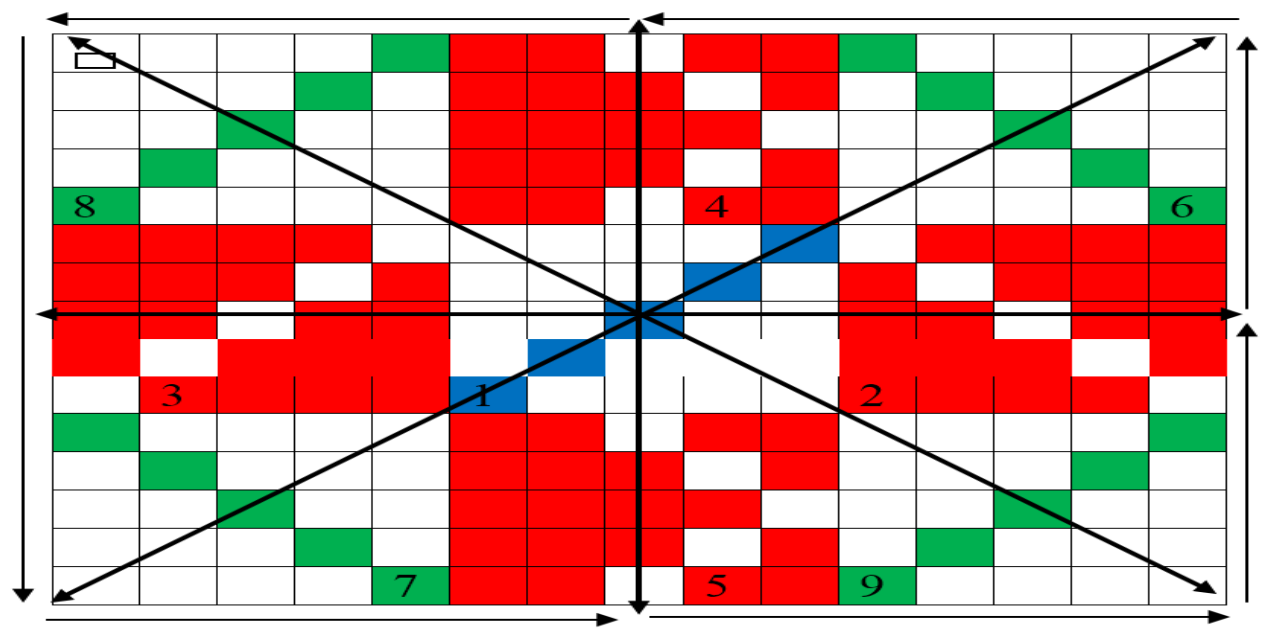

Figure 10:-The base according to the pattern is the pattern of the wrapping of the wrapping in the coordinate and diagonal axes.

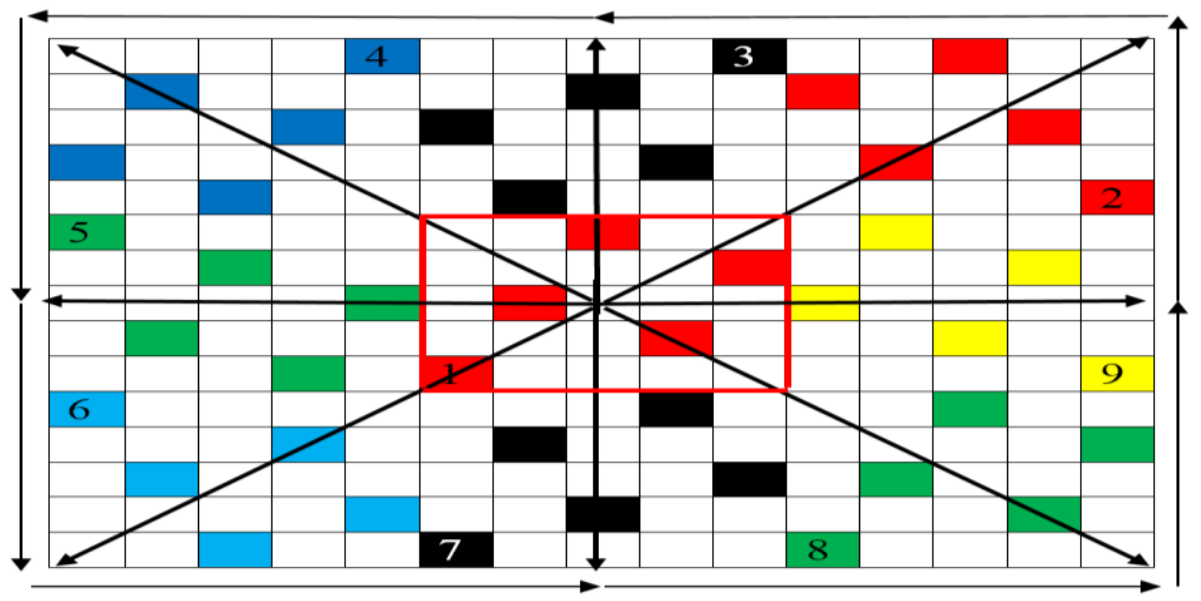

Figure 11:-The pattern according to the pattern $5 / 3$ The pattern obtained by rotating the satin axis around the counterclockwise and rotating it on the diagonal axis. 


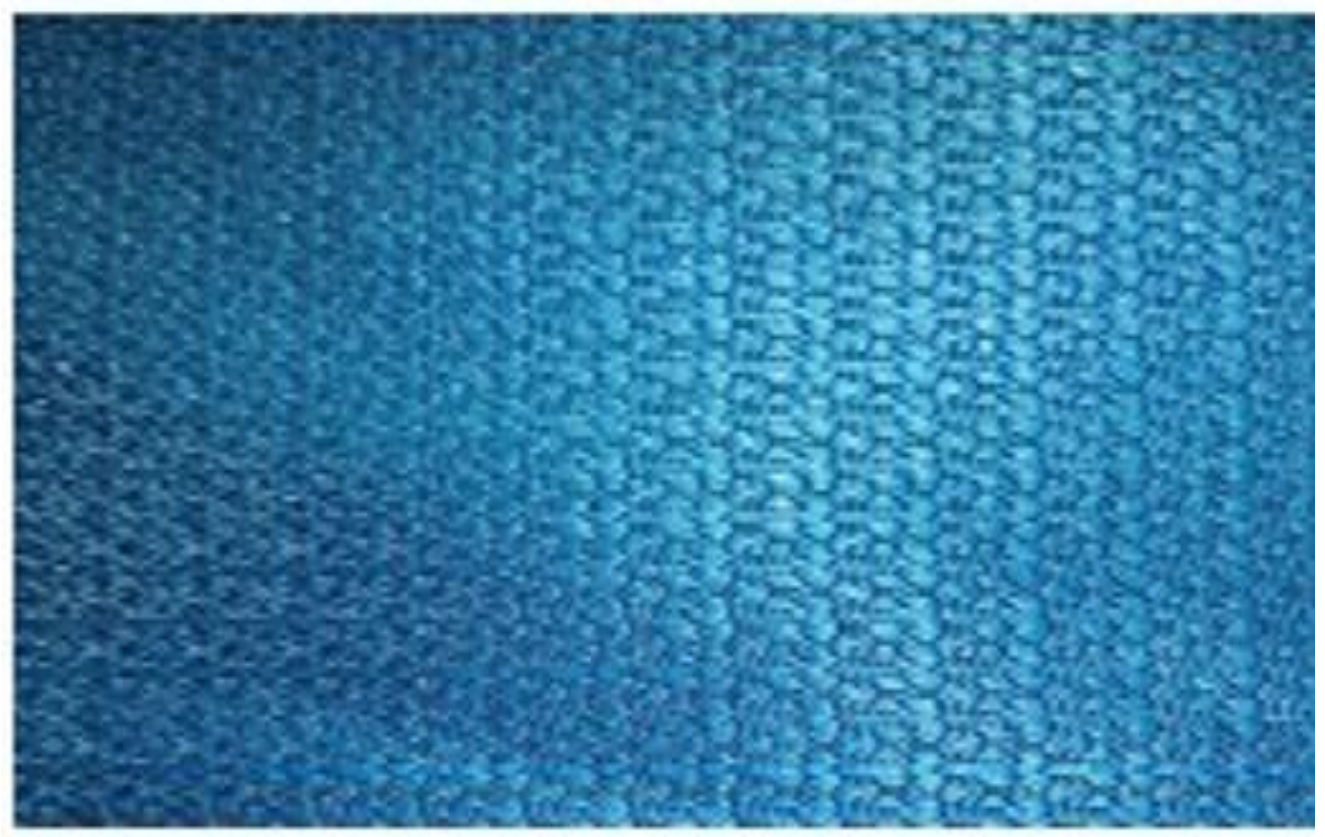

Figure 12:-Copy T-shirt embroidery on a modern reproduction machine by placing the base on the coordinate and diagonal arrows according to the pattern. Conclusion: This method allows enterprises to quickly design new woven fabrics on computers based on software, and to enhance their theoretical and practical knowledge for researchers.

\section{References:-}

1. Siddiqov P.S. Technology and equipment of textile products. Textbook for Universities. - Tashkent, Science and Technology. 2012. - B. - 16-17,31-35.

2. Olimboev E.Sh. Tissue structure theory. Textbook for Universities. - Tashkent, "Alokachi". 2006. - B. - 92-94.

3. Boymurodov BH, Daminov AD Weaving technology. Textbook for Universities. - Tashkent, Science and Technology. 2016. - B. - 221-226. 